\title{
Managing Insecticide and Miticide Resistance in Florida Landscapes $^{1}$
}

\author{
Nicole Benda and Adam Dale ${ }^{2}$
}

Insecticide and miticide resistance has become a familiar concern for landscape managers. Populations of the southern chinch bug (Blissus insularis), the most damaging insect of southern lawns, have been found resistant to chlorinated hydrocarbons, organophosphates, carbamates, pyrethroids, and neonicotinoid insecticides (Cherry and Nagata 2007, Vasquez et al. 2011). The American serpentine leafminer, Liriomyza trifolii, developed resistance to several chemical classes after heavy insecticide use in annual bedding plants in the 1970s and early 1980s (Leibee 1981). The twospotted spider mite, Tetranychus urticae, attacks over 1000 host plants (Migeon and Dorkeld 2018) and has been documented to be resistant to over 95 active ingredients around the world (Whalon et al. 2018).

Despite the prevalence and risk of resistance development, we can maintain long-term effective chemical control through diligent insecticide resistance management. With few new modes of action coming onto the market, landscape managers need to be good stewards of existing products. Ultimately, resistance management boils down to reduced exposure of pests to any one pesticide. Fortunately, there are many ways to reduce pesticide exposure to insects and still control the pests that affect our ornamental plants and lawns.

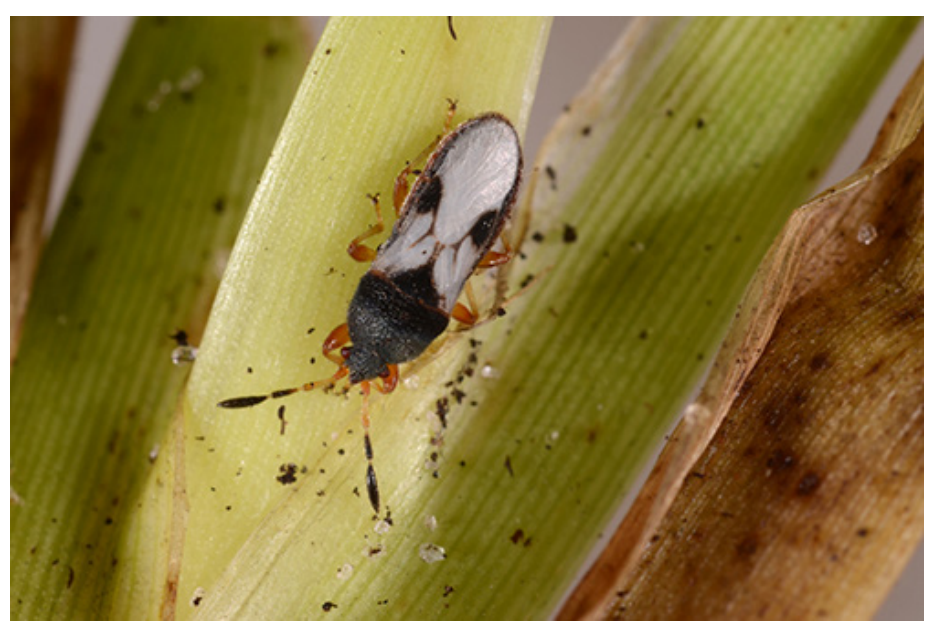

Figure 1. An adult southern chinch bug, Blissus insularis, the most damaging insect pest of turfgrasses in Florida. Populations of this pest have developed resistance to at least five classes of insecticides.

Credits: Lyle Buss, UF/IFAS Entomology and Nematology Department

\section{Important Definitions}

Resistance: Inherited (genetic) physiological and/or behavioral changes that allow some individuals within a population to survive and reproduce in the presence of a toxin. Resistant animals survive and reproduce, and their offspring are more likely to be resistant themselves, which leads to pest control failure.

1. This document is ENY-842, one of a series of the Department of Entomology and Nematology, UF/IFAS Extension. Original publication date April 2007. Revised February 2009 and July 2018. Visit the EDIS website at http://edis.ifas.ufl.edu. The original version of this publication were written by Eileen A. Buss, James F. Price, Elzie McCord, and Curtis Nagle.

2. Nicole Benda, post-doctoral asssociate; and Adam Dale, assistant professor, Department of Entomology and Nematology; UF/IFAS Extension Gainesville, FL 32611.

The Institute of Food and Agricultural Sciences (IFAS) is an Equal Opportunity Institution authorized to provide research, educational information and other services

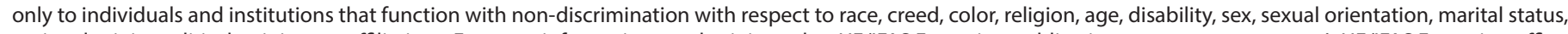

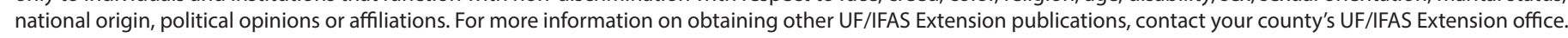
U.S. Department of Agriculture, UF/IFAS Extension Service, University of Florida, IFAS, Florida A \& M University Cooperative Extension Program, and Boards of County Commissioners Cooperating. Nick T. Place, dean for UF/IFAS Extension. 
Cross-resistance: When resistance to one insecticide confers resistance to at least one other insecticide with the same mode of action or another insecticide that targets the same molecular receptor site. For example, resistance to an organophosphate (like acephate) may confer resistance to another organophosphate (like malathion) or a carbamate (like carbaryl) because both groups are acetylcholinesterase inhibitors.

Mode of action: The mechanism or pathway by which an insecticide kills the pest.

Biotype: A group of insects with similar genetic background and common traits. In this case, genetics related to insecticide resistance.

\section{How does insecticide resistance occur?}

When a population of insects (Figure $2 \mathrm{a}$ ) is exposed to an insecticide, most of the insects die (Figure 2b). But a few naturally resistant individuals that possess the genes that confer resistance survive (white dots), and these survivors will reproduce (Figure 2c). Their offspring will inherit the resistance genes, and the population will become more resistant to this insecticide. When subsequent generations are treated with the same insecticide, the majority of the population shifts to predominantly resistant individuals,

- Susceptible individual

O Resistant individual

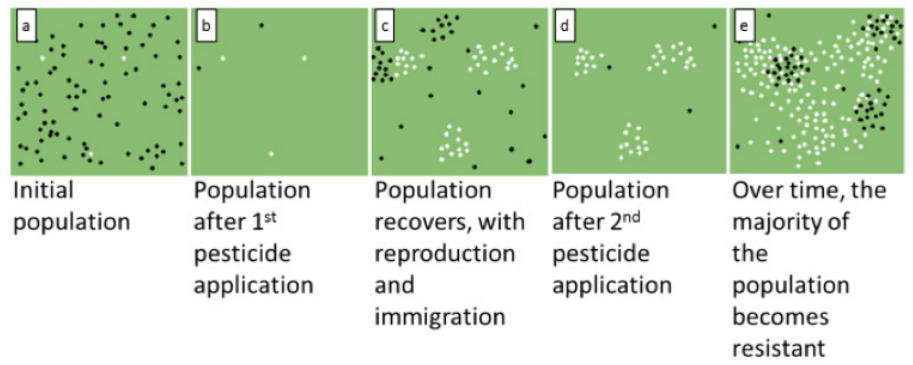

Figure 2. Timeline of insecticide resistance development.

leading to pest control failure (Figure $2 \mathrm{~d}-\mathrm{e}$ ).

Resistance can develop faster in insects or mites that reproduce quickly and have many generations in a year, have many offspring, and remain in the same area/plant/ habitat (such as mites, aphids, whiteflies, and thrips). These characteristics often translate to repeated exposure to consecutive pesticide applications to the same pest population, hastening the rate of resistance development.
At the biological level, pests can become resistant to pesticides by changing their physiology or behavior. The most common path to resistance is called metabolic resistance, where the resistant insect is better able than its non-resistant peers to detoxify or deactivate (break down) the toxin. Insects and mites may also change their exoskeletons ("shells") to prevent entry of the toxin, or they may sequester the toxin (safely store it within their bodies), or excrete it from their bodies. The target site of a resistant insect can also change so it will not respond to the toxin. Because most common insecticides affect the insect nervous system, these changes commonly are associated with the nervous system. Some of these changes may make the pest resistant to similar chemical compounds with the same mode of action (e.g., changes in the target site for a pyrethroid insecticide confers resistance to the whole pyrethroid class of insecticides). Behavioral changes like flying away or hiding during applications can also help insects by reducing their exposure to certain insecticide applications.

The key to reducing resistance is to avoid exposing multiple generations of a pest population to the same insecticide class. This can be done by following an integrated pest management (IPM) program and rotating chemical classes or sometimes using pesticide mixtures of different modes of action.

\section{Using IPM To Reduce Pesticide Resistance Development}

The best way to reduce pest population exposure to the same insecticide class is to spray that insecticide class less often. Use insecticides only when it is necessary to protect plants from serious injury. Rotate insecticide classes, and integrate cultural, mechanical, biological, and chemical controls to reduce pests more sustainably by promoting plant and ecosystem health.

\section{Guidelines for Using Landscape IPM}

- Sanitation reduces insect pests and diseases. Remove excessive plant debris from flower beds before, and periodically after, installing new plants.

- Before you purchase plants, inspect them to be sure they are pest-free.

- Look for pest-resistant plant species and varieties.

- Rotate species in annual flower beds.

- Follow fertilizer and irrigation recommendations. 
- Identify pest species and life stage to help choose the most appropriate pesticide and application time.

- Spot-treat when using pesticides so that natural enemies can recover in untreated areas.

- Use reduced-risk, pest-selective, and biorational pesticides that are softer on beneficial insects.

- Avoid calendar-based spray programs when possible. Spray when pest density reaches economic or aesthetic thresholds.

- Recognize high-risk pest populations where resistance can develop faster.

- Rotate insecticide chemical classes (See below for details).

Note: Using less pesticide does not mean using lower-thanlabel rates. Lower-than-label rates will allow insects with only a small amount of resistance to survive. These partially resistant insects are more common than highly resistant insects and, due to higher numbers, can provide an easy route to a fully resistant population.

\section{Insecticide Classifications}

Insecticides are classified by the way they affect insects at the molecular level, called the mode of action (MoA). The Insecticide Resistance Action Committee (IRAC) was formed in 1984 and provides insecticide and miticide number and letter designations on most insecticide labels that represent each compound's MoA (Figure 2). The numbers can also be found on the IRAC website. These numbers are a simple guide for applicators to incorporate chemical class rotations into their pest management programs.

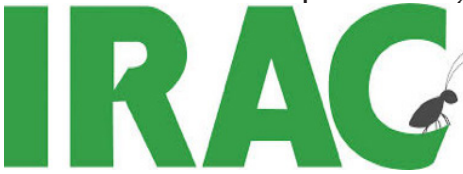

GROUP 4D INSECTICIDE

\begin{tabular}{|c|c|c|}
\hline GROUP & $\begin{array}{c}3 \\
4 a\end{array}$ & INSECTICIDES \\
\hline \hline GROUP & 28 & INSECTICIDE \\
\hline
\end{tabular}

Figure 3. The Insecticide Resistance Action Committee (IRAC) classifies insecticides by number and letter designations based on their mode of action, or the mechanism by which they kill a pest. Insecticide labels will have the IRAC number and letter designation at the top of the label, which appears as shown in this figure.

A few products (such as insecticidal soaps and horticultural oils) have no IRAC codes because they kill insects through physical contact and have no specific physiological mode of action. Their use is unlikely to result in pest resistance, so rotating them is not necessary. These products are great to incorporate into an IPM program to reduce your pesticide use and the likelihood that pests will develop resistance to synthetic pesticides.

\section{Insecticide Class Rotation}

The objective of insecticide class rotations is to alternate pesticides with different modes of action so that a single generation of a pest is exposed to only one insecticide class, but the population experiences more than one class over time. This strategy assumes that a pest with resistance to one mode of action (e.g., a pyrethroid) will not be resistant to another mode of action (e.g., an organophosphate).

Rotate the order in which you use insecticides by class if multiple applications are required. Use the IRAC numbers on the label to select a different mode of action each time before returning to a previously used one. An example of a rotation could be: Talstar (pyrethroid), Purespray Green (horticultural oil), and then Merit (neonicotinoid). Using products with different active ingredients or trade names will not work to avoid resistance development if the active ingredients are from the same chemical class, e.g., Talstar $=$ bifenthrin (pyrethroid), Sniper $=$ bifenthrin (pyrethroid), Tempo $=$ B-cyfluthrin (pyrethroid), Astro $=$ permethrin (pyrethroid).

Keep in mind that rotations should be based only on the IRAC number, not the letter in the classification. Altus (flupyradifurone, Group 4D) is a butenolide in the same pesticide group (Group 4, nicotinic acetylcholine receptor competitive modulators) as neonicotinoids like Merit (imidacloprid, Group 4A) and Arena (clothianidin, Group 4A). Therefore, a pest population resistant to IRAC Group 4D may also be resistant to IRAC Group 4A.

\section{Mixtures}

Pesticide applicators often appreciate applying mixed pesticides because they can reduce the number of applications and/or broaden the spectrum of pest control. There are also several commercial products sold as mixtures for use on turf and ornamental plants (e.g., bifenthrin + imidacloprid; zeta-cypermethrin + bifenthrin + imidacloprid).

Simultaneously applying a mixture of active ingredients and insecticide classes exposes pests to more than one toxicant. This strategy may mitigate or delay resistance development only if 1) there is no cross-resistance between the products and 2) they are applied during the period when products have overlapping residual activity. Although mixtures include multiple modes of action, repeatedly applying them is not considered a rotation and may encourage resistance to multiple classes over time. 
Pesticide applicators can make their own mixtures unless the product labeling prohibits it. This practice comes with several important considerations. Do not mix products with the same IRAC number. The IRAC committee notes that mixtures only act to mitigate resistance development while both pesticides are active, so they recommend mixing pesticides with similar residuals. Also, keep in mind that mixing compounds runs the risk of reducing their effectiveness (antagonism) or causing plant damage (phytotoxicity). Check the label to make sure the products are compatible. If you aren't sure, test a small quantity before preparing a tank. You do not want to end up with a big glob of goo in your spray tank or a landscape of dead plants. Consider using synergists, which are non-pesticide materials that can boost the efficacy of pesticides. A common synergist is piperonyl butoxide ( $\mathrm{PBO}$ ), which is often added to pyrethroids or pyrethrins.

\section{Is it resistance?}

Finally, it is important to realize that resistance isn't always the problem. If you have had failed control efforts, there are a few things to do before considering alternative management approaches.

- Be sure you have properly identified the pest.

- Monitor the insect population. Products can take time to reduce a pest population, and damage can linger a while after the insects are gone.

- Make sure you're applying products correctly. Try applying the highest label rate. Check your walking speed, equipment calibration, and wind speed to make sure the correct volume of product is contacting the infested parts of the plant. Soil-dwelling pests, such as grubs or mole crickets, can be difficult to reach with insecticides unless those insecticides are watered in with the proper amount of supplemental irrigation or there is adequate rainfall to allow them to penetrate the soil and reach the grubs.

- Consider non-ionic wetting agents (a type of adjuvant) to increase penetration and coverage onto plant material. Check your water $\mathrm{pH}$, and add a buffer to your spray mixture if needed.

- Follow label instructions regarding irrigation-either watering the product in or allowing it to dry after application.

\section{Know the Chemicals You Are Using, and Use All the Tools in Your Toolkit}

Be familiar with the insecticides and miticides you're using. Read the product labels and make note of the IRAC classification number. Use your UF/IFAS Extension resources. Implement other IPM techniques as well. Use pest-resistant varieties and appropriate cultural practices, and conserve natural enemies to help sustainably control pests in our Florida landscapes.

\section{Resources to Help Choose Insecticides for Rotation}

- IRAC's Insecticide Mode Of Action Classification: http:// edis.ifas.ufl.edu/pi121

- IRAC MoA smartphone app

- EPA reduced-risk pesticides: http://edis.ifas.ufl.edu/pi224

\section{Useful EDIS Publications}

More information on IPM in landscapes and insect identification is available on the EDIS website (http://edis.ifas.ufl. edu).

- Landscape Pest Management in Florida: http://edis.ifas.ufl. edu/topic_landscape_pests

- Landscape Integrated Pest Management: http://edis.ifas. ufl.edu/in109

- Natural Products for Managing Landscape and Garden Pests in Florida: http://edis.ifas.ufl.edu/in197

- Guidelines for Purchasing and Using Commercial Natural Enemies and Biopesticides in North America: http://edis. ifas.ufl.edu/in849

- Insect Pest Management on Turfgrass: http://edis.ifas.ufl. edu/ig001

- Insecticides Used in the Urban Environment: Mode of Action: http://edis.ifas.ufl.edu/in077

\section{Avoid Insecticide and Miticide Resistance}

Do not expose multiple generations of pests to products with the same mode of action. This is tricky in Florida, where generations can overlap quite a bit, especially towards the end of summer. Table 1 below lists some general guidelines to help: Approximate periods (in weeks) for one generation of common insects or mites to develop under 
warm and cool Florida production temperatures. This table is from "A dresser drawer method for managing insect and mite resistance in ornamentals" by J. F. Price and C. A.

Nagle (2008).

\section{References}

Cherry, R., and R. Nagata. 2007. "Resistance to two classes of insecticides in southern chinch bugs (Hemiptera: Lygaeidae)." Florida Entomologist 90(3): 431-434.

Hoy, M. A. 1999. "Myths, models and mitigation of resistance to pesticides." In Insecticide Resistance: From Mechanisms to Management (ed. I. Denholm, J. A. Pickett, and A. L. Devonshire), pp. 111-119. New York: CABI Publishing.

Leibee, G. L. 1981. "Insecticidal control of Liriomyza spp. in vegetables." In Proceedings of the IFAS-Industry Conference on Biology and Control of Liriomyza leafminers (ed. D. J. Schuster), pp. 216-220. Gainesville: University of Florida Institute of Food and Agricultural Sciences.

Migeon, A., and F. Dorkeld. 2014. Spider Mites Web: A comprehensive database for the Tetranychidae. http://www. montpellier.inra.fr/CBGP/spmweb. Accessed on Mar. 22 2018.

Onstad, D. W. 2008. Insect resistance management: Biology, Economics and Prediction. Elsevier Ltd., London. 305 pp.

Pedigo, L. P. 2002. Entomology and Pest Management, 4th edition. Prentice Hall, Upper Saddle River, NJ. 742 pp.

Price, J. F., and C. A. Nagle. A Dresser Drawer Method for Managing Insect and Mite Resistance in Ornamentals. 2008. ENY-750. Gainesville: University of Florida Institute of Food and Agricultural Sciences.

Tabashnik, B. E. 1990. Modeling and Evaluation of Resistance Management Tactics. In Pesticide Resistance in Arthropods (ed. R. T. Roush and B. E. Tabashnik), pp. 153-182. New York: Chapman and Hall.

Vasquez, C., R. N. Royalty, and E. A. Buss. 2011. "Susceptibility of Blissus insularis (Heteroptera: Hemiptera: Blissidae) populations in Florida to bifenthrin and permethrin." Florida Entomologist 94(3): 571-581.

Whalon, M. E., R. M. Mota-Sanchez, R. M. Hollingworth, and L. Duynslager. Arthropods Resistant to Pesticides Database (APRD). Available at: http://www.pesticideresistance.org. Accessed on: Mar. 222018. 
Table 1. Guidelines for predicting pest insect or mite development rates to inform the timing of pesticide applications.

\begin{tabular}{|l|c|c|}
\hline \multicolumn{1}{|c|}{ Insect/mite group } & \multicolumn{2}{c|}{ Generation time (in weeks) } \\
\hline Aphids & Warmer temperatures & Cooler temperatures \\
\hline Spider mites & 1 & 2 \\
\hline Thrips & 1 & 2 \\
\hline Liriomyza spp. leafminers & 1 & 4 \\
\hline Whiteflies & 3 & 4 \\
\hline Moths/caterpillars & 3 & 6 \\
\hline Chinch bugs & 4 & 8 \\
\hline
\end{tabular}

